\title{
Young People, Researchers and Benetton
}

\author{
Contest Interpretations of a Benetton Advertisement Picture
}

\author{
JANNE SEPPÄNEN
}

In the spring of 1997, four Benetton advertisements were placed in front of Finnish candidates for the matriculation examination. One portrayed a nun and a priest kissing, another featured a black wolf and a white lamb, a third one was a picture of multi-coloured condoms lined up in straight rows, and a fourth portrayed a "family of the future", two adults with a child in between them wrapped in a green blanket. ${ }^{1}$

The pictures were a part of that year's examination in the Finnish language as a mother tongue in which the young people were asked to write an essay with a title of their own on the basis of the material distributed to them ${ }^{2}$. The subject was eagerly seized upon by the students. Thousands of essays were written, and the students added their own opinions to the Benetton debate that has churned for years in the public realm. However, their interpretations were to be assessed only by their own teacher and the matriculation examination board - that is, until this article was written.

Perhaps Benetton as a phenomenon has been too trendy for sociologists or researchers in the field of communication studies to have the nerve to show an interest in the subject. Searching through the databases of social sciences (September 1998) results in only a few texts that deal with Benetton. The most central of these are "Dream Utopias, Nightmare Realities" (1993) by Les Back and Vibeke Quaade, "Consuming Social Change" (1994) by Henry A. Giroux, and "Images of Planetary Danger" (1994) by Michael Shapiro. Sociologist Pasi Falk has also written about Benetton. His article "The Benetton-Toscani Effect: Testing the Limits of Conventional Advertising" was published in 1997. In

Department of Journalism and Mass Communication, University of Tampere, FIN-33014 University of Tampere, js48301@uta.fi the field of communication studies, Serra A. Tinic's "United Colors and United Meanings: Benetton and the Commodification of Social Issues" that was published in the Journal of Communication in 1997 stands out.

There are three things that are common to all of these texts. Firstly, they attempt to critically assess the meaning world of Benetton pictures and/or join it as part of other culture: advertisement and pictorial representation of race or globalisation. Another quality, the primary one where this article is concerned, is that the articles rely on so-called textual interpretations. In this case, the researcher interprets the meanings of the Benetton adverts and campaigns in the light of his/her own theoretical knowledge, in a historically limited cultural state which can be termed scientific discourse. The third common feature springs from the fact that not one of these articles consider what the above-mentioned factor possibly means in regard to the interpretations. The much-debated reflexivity therefore does not seem to reach the field of scientific work, in so far as reflexivity is understood as self-reflexivity; namely, consideration of the grounds and discursive state of one's own interpretations.

In this article, I actually only deal with one question: what is the relationship of the researcher's interpretation to the interpretations of the pictures by the young people? It is significant to find an answer to this question, because in the field of social scientifically-oriented photography research, little research is conducted on the reception of an image. In Finland, an exception is Pauliina Arva's work Pictures and Images of Health Education (1991), in which she illuminates the reception of health education. If the matter is looked at from the broader horizon of communications research, the reception of different media texts has already been long researched. However, 
to my knowledge even in this area no comparative situation has been set up between researcher and layman interpretations of the same media text. Therefore, on the general level, the question is of how a researcher's theoretical interpretation of a media text is related to interpretations about it made by a broader audience.

These topics should open up the opportunity to clarify many other questions such as young people's attitudes towards advertising, racism or gender. These themes indeed take a high position, but my analysis places emphasis on the consideration of the interpretative differences between the young people and the researchers. Hence, I do not only utilise the researcher's findings to explain the interpretations made by the young people, but also their writings create a textual field against which the researchers' interpretations can be examined. This setting assists in assessing the researchers' texts as ascientific media texts, which interpret reality with the aid of the authority that theory and science allow them. My own role could be best describe as that of a referee who assesses the game and only interferes when necessary. However, as in any game, the referee can be partial to one of the two teams. S/he can steal the stage and take the leading role, whether or not s/he can admit it, trapped in his/her own interpretations.

A word about the limits of the article. I do not attempt to answer the question of why the interpretations differ from one another, because to do that would have required taking the contexts of the texts into account, a job too big to do for one single article. However, the reader can perceive certain tentative answers as the analysis proceeds. Regarding the essays, I focus only on those analyses that concern the picture called Family of the Future ${ }^{3}$. These interpretations I compare only to the article by Les Back and Vibeke Quaade because it analyses the same picture. Certainly there are different focuses on the other articles to be found, but they do not analyse Family of the Future which is discussed here.

First I go through the central themes of Back and Quaade. Simultaneously, the history of the Benetton campaigns is briefly delineated. Then I construct a small theoretical tool, the concept of difference, with which I unlock the interpretations the young people have presented of the picture. Lastly, I consider how Back and Quaad's researcher interpretation relates to the interpretations of the young people.

\section{Benetton and the Grammar of Race}

In their article, Les Back and Vivebe Quaade consider Benetton advertisements' relationship to racism, that is, the "grammar of race" in the advertisements, as they put it. In addition, they are interested in the role of documentary photographs as part of the company's advertising. All and all, the researchers' attitude is critical: Benetton's pictures maintain and build racial stereotypes and racism.

Back and Quaade divide Benetton campaigns into three time periods, which they have termed the stages objectification and fragmentation, racialisation and ambiguity, and pseudo-journalism. The latter they also call pseudo-documentary. The pictures given to the matriculation examination candidates to analyse are chiefly from the middle period. Naturally, the newest campaigns that utilise disabled children and people on the death row are missing from the article that was published in 1993.

The era of objectification and fragmentation begins in 1984 . The company gives up product-oriented advertising and develops a new strategy with photographer Oliviero Toscani in the lead. Benetton adverts are filled with young people, and along with them - according to Benetton - cultural diversity is highlighted. The campaign that runs in 14 countries is called All the Colors of the World. What, then, is it in this stage that gives rise to its characterisation with the concepts of objectification and fragmentation?

According to Back and Quaade, Benetton turns the features of national cultures into stylistic differences between individuals, and hence fragments their national identity. Apparently this is to be understood so that the connections of the young people appearing in the pictures to their ethnic groups disappear, and are substituted with a kind of a play of differences which is superficialised into style. Objectification, in turn, means that cultural differences are objectified into goods on sale. "The paradox demonstrated by the campaign is that the images of international communication and unity is realized by emphasizing difference and creating fetishistic images of nationalisms, crass racial stereotypes and images of otherness which are fragments and objectified", Back and Quaade (ibid., 68) write.

The researchers place emphasis on two things. Firstly, pictures presenting difference between people are tightly connected with Benetton's own dis- 
cursive space where race and ethnicity are represented as an unchanging and everlasting thing in essence. Secondly, Toscani exploits the image of the borders between cultures or ethnic groups in order to awaken the idea of commitment to international harmony. This crossing of differences is harnessed to serve Benetton's image and to create a high-quality brand. Its development enables marketing without presenting the actual product at all.

This phase ends in 1989. Ideal-type bolstering of racial harmony and internationalism disappears from pictures and is replaced with direct or metaphorical representation of racial oppositions. At the same time, people's qualities are naturalised; they are made into myths in the sense that Ronald Barthes means. Back and Quaade (ibid., 69) quote Barthes: "In passing from history to nature, myth acts economically. It abolishes the complexity of human acts, it gives them the simplicity of essences."

This historical conversion into the natural becomes apparent in the portrait in the picture Family of the Future. To quote Back and Quaade (ibid., 69), "(I)n the absence of any naked male figure, the women and children are aligned to nature, and constructed as the locus of transcendental love. Race, femininity and childhood are articulated within a mutually reinforcing discourse, in which social constructions are naturalised by the association between women as nurturers and children as innocents."

It is typical to this particular phase of the campaign that the concept of difference is restored with features that are stereotypical and characteristic to each race. Blacks are black, Asians have slanted eyes, whites are blond. According to Back and Quaade, in Family of the Future the races appear distinct, not intermingled.

The researchers take a couple of other pictures connected with the same phase under their scrutiny. The first one portrays hands cuffed together; a black and a white man. The second picture shows a black woman nursing a white child.

Benetton was forced to withdraw the adverts from the U.S. market due to the controversy they caused. The breastfeeding picture was seen as a reference to slavery, with black women as wet nurses, and also to black women's position as the object of white men's desire. Moreover, the handcuff advert caused a brouhaha on both the old and the new continents. The black man was interpreted as a criminal and the white man as a representative of law. Many saw the picture as openly racist. However, at the same time in France neo-fascist and racist groups

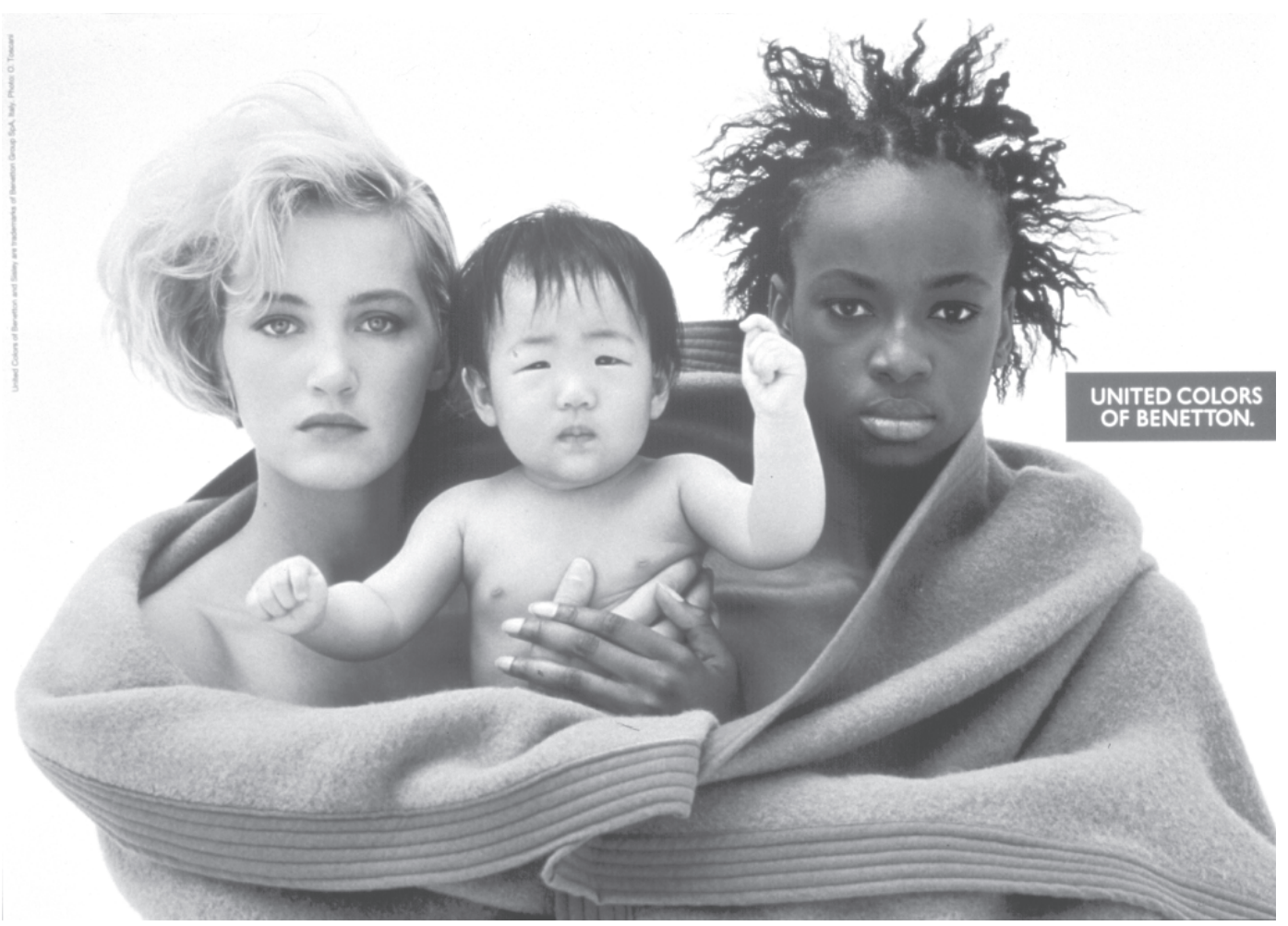


threw a tear gas grenade into a Benetton shop. In other words, the pictures aroused, de facto, reactions totally contradictory with each other.

Back and Quaade expound on the interpretations sparked off by the adverts with the aid of Stuart Hall's well-known encoding/decoding pair of concepts. The Benetton adverts are produced (encoded) under the influence of a certain technical and productional structure, and interpreted (decoded) in different societal practices. Therefore, "decoding Benetton advertising can involve both the question of utopian codes of multiracial harmony /.../ alongside crass, historically and geographically situated racisms." (ibid., 71)

The third phase of the Benetton campaign (pseudo-documentarism) began in 1992. Oliviero Toscani came out of the studios and began exploiting the genre of documentary photography. Portraying racial opposites shifts into the background and is replaced by pictures of a car that has exploded, a dying AIDS patient, a newborn baby. Benetton uses genuine photographs of catastrophes in its advertising. One of this type of representation is a picture taken of the back of a black soldier with a Kalashnikov strapped on his back, a human shinbone in his hands. According to Back and Quaade the picture communicates the notion of Africans as barbaric cannibals. Another much discussed photograph is the shot of the death bed of David Kirby who perished from AIDS.

According to Back and Quaade, the Benetton way of utilising documentary photographs in its advertising violates the status that the genre holds in the society as a true representation of reality. The advertising represents a totally opposite genre that connects with fantasy. Hence, the debate that criticises the Benetton campaign is not merely a debate about the content of the pictures, but also a struggle over their form. Benetton violates the genres of both documentary photography and advertising by mixing them together. Back and Quaade join in with the view according to which documentary photographs allow the viewer voyeristic pleasure as they show, at a safe distance, events and dangers with which western people rarely meet. Therefore, the pictures distance the watcher and the watched from each other, and the pictures become fetishes and spectacles of catastrophes: "The documentary photograph serves to redefine the superordinate position from which the white European sees the world. We refer to this as the catastrophe fetish, and we suggest that this is a central theme in European news production. Equally, the advertising shot focuses on the commodification of fantasy, and sells the pleasure of consumption. Thus both forms exploit the enjoyment engendered by spectacle." (ibid., 78).

In Back and Quaade's view, all Benetton campaigns restore racial prejudices in a more subtle way than ever. "Images of cultural difference become crass caricatures, and stark racial stereotypes are reinforced to generate crude oppositions, reducing the complexity of cultural and racial identities to essences. While advocating harmony, Benetton produces images of racial and cultural purity. Racial difference is naturalized and then the tenets of racial common sense are endorsed." (Ibid., 79)

The Benetton adverts conceal white eyes, that is, we are not allowed to know how we ourselves look like in the eyes of the people in the pictures. Neither do the photographs reveal who was holding the camera. Furthermore, the power mechanisms connected with representation remain hidden. The pictures provide material for building identity only for white viewers, with the terms dictated by Benetton. The consequence of all this is that the objects of the photographs do not communicate. They don't have a voice of their own.

\section{The Meanings of the Concept of Difference}

After the interpretations of Back and Quaade it is rather confusing to read the essays of the young people. At first, it feels as if the researchers had, in their harsh analysis, hit the target in many things. For instance, not one of the matriculation examination candidates asked whose voice it is that the pictures speak with, who was allowed to determine their means of representing difference or who held the camera. Yet, this is not the whole picture. For a more detailed analysis, I extracted the interpretations concerning Family of the Future out of the essays. The outcome of the process was a minature database, which consisted of 37 characterisations of the picture. Out of these, two central frames or discourses can be perceived: gender and ethnicity. The first frame refers to interpretations in which, in one way or another, the gender of the people in the photograph comes up with the linked differentiations, such as woman/man. The other frame consists of interpretations in which 'race', origin or difference in general is referred to. Prior to entering the details of the interpretations there is reason to particularise the concept of difference a little.

Stuart Hall (1997, 234-238) conceptualises four ways of understanding the problem of difference. The first one of them is anchored to Saussurean linguistics. According to this view, differences are es- 
sential because they enable the birth of meaning. According to Ferdinand de Saussure's well-known conception the entire linguistic system and, via that, the meanings of individual signs arise from their difference to other signs. For instance, the pair black/white constructs such a difference. The previously mentioned pair of opposites also brings forth the binary quality of difference, where meaning is only created through extreme opposites. Hall (ibid., 235) summarises: "So meaning depends on the difference between opposites. However, when we discussed this argument in chapter 1, we recognized that, though binary oppositions -white/black, day/ night, masculine/feminine, British/alien - have great value of capturing the diversity of the world within their either/or -extremes, they are also a rather crude and reductionist way of establishing meaning."

Therefore, binary thinking is simultaneously essential, practical and tragic, since more subtle differentiations and the sense of nuance go missing or, at least, are in the danger of vanishing into polarised meanings.

Hall seconds the notion according to which there exists only relatively few neutral binarities. Nearly always, an unbalanced power relationship is constructed in between the binary poles. Hall sums it up: "We should really write white/black, men/ women, masculine/feminine, upper class/lower class, British/alien to capture this power dimension of discourse."

It could be added to this that already the reduction into binary oppositions is a manifestation of power's capacity to produce borders and meanings of expressions. Hence, power is not constructed only in the unbalance of binarity, but already in the binarity itself as a custom of linguistic perception and thinking.

Another theoretical explanatory model connected to difference also arises from linguistics, though from a slightly different direction. Here, the central figure is Mihail Bahktin. In this view, the meaning of difference springs from the notion that it is only possible to construct meanings in dialogue with another. When I release this text from my own hands and others read it, I am no longer able to keep its meanings to myself - if, strictly speaking, they have ever even been mine. In any case, the meanings of the text are reborn in the interpretations of others, and those I might no longer even recognise as my own. For this reason, meaning can never be definitively fastened. It is at all times exposed to the birth of differences, since dialogue produces differences. Naturally, this matter does not exclude the fact that meanings are always shared or that there are regularities in interpretations.

The third meaning of difference comes from anthropology. "The argument here is that culture depends on giving things meanings by assigning them to different positions with a classification system. The marking of 'difference' is thus the basis of that symbolic order which we call culture." (ibid., 236) One of these forms of making a distinction is classifying people into "us" and "others"; then an alien that turns up among us forms a threat to the already established system of differences and categorising. It is attempted to normalise the situation by keeping one's own territory as pure as possible and by closing the alien off by keeping him/her outside. This does not necessarily mean a physical banishment but, just as well, integrating the alien into "our" cultural orders; honing the rough ends of difference away. According to Hall, denying difference also makes it paradoxically alluring. This is the allure of the taboo.

The fourth and the last theoretical model concerning difference originates in the traditions of psychoanalysis - or, should I say, psychoanalyses. From these points of departure, other people are essential when it comes to the forming of identity, subjectivity and sexual identity. Identity is always formed through identification and, therefore, creating differences, the object of which is often another person or some quality of theirs. Identity work is two-dimensional motion, the reflection of oneself to others and devouring others inside oneself. The psychoanalytical explanation model differs from the three others perhaps most significantly in the notion that it emphasises the subconscious character of exploiting differences and their formation. Therefore, a subject can not consciously control anything but a part of those forces that construct his/her self through producing differences.

Hall considers that none of these four models excludes any of the others. He also stresses that difference is always ambivalent, contradictory: "It can be both positive and negative. It is both necessary for the production of meaning, the formation of language and culture, for social identities and subjective sense of the self as sexed subject - and at the same time, it is threatening, a site of danger, of negative feelings, of splitting, hostility and aggression towards the 'Other'. (Hall ibid., 238).

Now, while keeping in mind the four different logics of difference, it may be asked how the differences connected with gender and ethnicity are formed in the interpretations of the young people. 


\section{The Youngsters' Interpretations and the Voices of Benetton}

\section{Gender}

In Family of the Future there are three persons: two adults and a child in between them. All are wrapped up in a green blanket. The gender ${ }^{4}$ of the person on the left is obvious to the writers: all interpret her a woman. None pay any attention to the gender of the child. The actual interpretative differences begin to take a form where the person on the right is concerned. Of the people writing about the picture, 16 construe the person as a man, 20 as a woman, and one left the gender issue open. Of the youngsters who saw the person as a man, 10 were women. A few writers referred to the ambiguity of the person's gender (for instance, "a masculine type of a woman"), but nevertheless positioned the gender into one or the other category.

Recognising gender is a significant matter, since it determines other analyses arising from the picture. For instance, the characterisation "family" gets quite different meanings depending on how the gender of the picture's black person is defined. In fact, the gender of the person in question is one of the key meanings of the picture that creates a great deal of interpretative ambivalence regarding the entire portrait.

The differences in defining gender at any rate tell that some of the messages in the picture are obviously unclear. They do not provide the viewer with an unambiguous sign system. In spite of this, not one of the writers indicated the possibility that the person could be, say, androgynous. Neither did any of the writers bring up the notion that Oliviero Toscani could possibly intentionally play with the gender issue. Interpreting the person to be of one gender or the other is a tell-tale sign of the binary quality of gender-related thinking. A person must have a certain clear sex, s/he must be able to be defined either a man or a woman; there are no other genders. Here, the examineés quite faithfully fulfill that cultural principle, which Judith Butler characterises as the heterosexual matrix ${ }^{6}$ (Butler 1990, 151) which provides only two 'normal' identity positions: man or woman.

Holly Devor indeed notes in her book Gender Blending: Confronting the Limits of Duality how people, even in indistinct situations, attempt to construe a person's gender as either/or, and usually as male. She relies on Kessler and McKenna's research, which was conducted in the 1970's. In this research, people were shown drawings of a human being in which the distinctive marks of gender (such as, clothing and hair) varied and were partially contradictory, and asked to determine the sex of the person on the basis of the clues they saw. "The result of this study strongly suggested that people see maleness whenever there is any indication of it. A single strong visual indicator of maleness tended to take precedence in the attribution process over almost any number of indications of femaleness." (Devor 1989, 48).

My own eyes do not find explicit indications of the person's gender, the picture seems to be extremely ambivalent. Yet, there is one strong indication in the picture which begins to construe a sex for the black person. The tendency is to see the person as a man, because s/he is in a man's place in the traditional trinity of a nuclear family. Yet, it can be equally thought that precisely due to the crumbling of the traditional family model, room is made to see the person of the picture as female.

One candidate interprets the picture in the following way:

Toscani's second human portrait represents a small family. The parents, dark and light skinned, are side by side. There is a small child in between them. The threesome is tightly wrapped up in a thick, green blanket. At first glance, the picture hardly upsets many people: parents and a child. Only as the picture is more closely examined, is it revealed that the darkskinned person is a woman! Also, this picture pokes at Christian traditions. The first impression of an Adam and Eve-like idyll is shattered into an appalled fussing over the debauchery of lesbian culture and a heated debate over the lesbian couple's suitability as parents. The parents in the picture seem to be aware of their uncertain status. Their expressions are grave, snuggling up inside the blanket provides protection against the threatening outside world. On the other hand, the picture also communicates closeness and caring, as well as shared responsibility. The arms of both parents are around the child, tenderly but firmly. Apparently an adopted Chinese child is a reminder of a topical subject, the destiny of Chinese girl children. In addition to Christian circles, the picture must have also upset other conservative groups. Sexual deviance, racial differences and parenthood are all topics that call for quite a bit of tolerance in order not to provoke. Then again, the picture probably delighted the advocates of ethnic groups, sexual minorities and human rights. (2M1) 
The writer starts with description of the first impression. When s/he takes a little closer look at the picture, the more concealed meanings begin to be revealed to him/her. The writer thus understands looking at a picture as a time-consuming and multifaceted activity. Now the question is not only of different people perhaps interpreting a picture in different ways. Moreover, the same viewer can read a picture in various ways. It is possible that in another situation the writer would have taken a mere glance at the picture and automatically interpreted the person as male. Therefore, an individual photograph can include meanings that are contradictory with each other, which, according to the writer, arouse anger, horror and debate: "The first impression of an Adam and Eve-like idyll is shattered into an appalled fussing over the debauchery of lesbian culture and a heated debate over the lesbian couple's suitability as parents."

The writer sees the picture as needling "Christian traditions". The word 'also' in this connection indicates that the writer also understands the other pictures under examination as somehow involving offending Christian values. The reference to Adam and Eve brings with it religion-related meanings, even if in a way that feels to be a little far-fetched. This interpretation presumably is based on the fact that Benetton with its campaigns has had numerous infamous conflicts with the Roman Catholic Church. In any case, the past and the present times meet in the writer's interpretation; the Christian tradition crumbles into "a heated debate over the lesbian couple's suitability as parents".

Interpretatively, the situation is delicious. The writer uses the concept of family to characterise the entity of two persons and a child, which simultaneously flagrantly disintegrates the concept of family. It can be seen in the writer's interpretation that an individual photograph can simultaneously maintain and disintegrate a cultural structure, in this case, the traditional family (man, woman and children). It is precisely here that a subtle and at the same time paradoxical dynamics of difference is at work. The traditional family is part of the symbolic order of culture, and, according to the psychoanalytic conception, the central birth place of gender difference. The internal contradictions and ambiguity of the picture have such an effect that the concept of family can no longer be used "purely" in connection with the picture in question. While the meanings of a family begin to deteriorate, they move on to new territories; the parenthood of a lesbian couple. The man/woman binarity of the nucleus of the family dismantles, and it is this dismantling process that the writer interprets as the internal tension of the picture. In the interpretation of the writer, the picture unravels the heterosexual matrix by bringing forth a woman as the object of desire by another woman, but at the same time it upholds the very same matrix since the binarity of gender maintains untouched. Still there are only two possible sexes: man and woman.

The writer loads his/her interpretation with rather clumsy rhetorical effect and highlights the picture's capacity to arouse mixed feelings. The origin of such dramatism is easily traced back to the stir that has churned around Benetton pictures all the way since the 1980's. Benetton's trademark is to upset, and hence it is a plausible interpretative framework also for this picture.

In fact, the writer's own position is that of an outside observer who presents his/her opinions to a certain audience. In this case, the audience consists of the Finnish language teacher and the judge of the matriculation examination board. A matriculation examination essay is fundamentally a maturity test and a form of self-representation, which might not actually have all that much to do with what the writer really thinks him/herself. In writing the essay, a candidate produces a performance from him/herself to be assessed by the judge's eyes, which fact also determines the generic character of the text. Going too much over the top is avoided, it is better to play it safe rather than take pointless risks. Therefore, the manner of writing about the pictures is of ten a sensible matter-of-fact style, perceptive of phenomena and, at times, cultivating one's 'own opinions'.

The writer presents the people in the picture with a positive tone of voice: "The parents in the picture seem to be aware of their uncertain status. Their expressions are grave, snuggling up inside the blanket provides protection against the threatening outside world. On the other hand, the picture also communicates closeness and caring, as well as shared responsibility. The arms of both parents are around the child, tenderly but firmly." Thus the adults in the picture are capable of caring for the child and offering it love, responsibility, and tenderness.

The role of the blanket is central. It becomes a metaphor for the family's social bond, even if the writer does not directly say this. The blanket is a protective measure against "the threatening outside world" similarly as the family gives protection to its members. Here a new binarity is built which is dressed in the form of a spatial binarity. The inside signifies safety and the identification basis provided by one's own group. Hence the blanket grows into a 
boundary marker for the us/others differentiation in two senses. Firstly, it signifies the boundary marker of a minority (a lesbian couple) to the majority (heterosexual couples), which isolates the minority onto a separate island. At the same time, the blanket crystallises the notion that minorities can protect themselves from the outside world by forming a community the internal bonding of which is as firm as that of a traditional family. The writer is capable of giving character to the people's emotions in that "threatening" situation in which s/he them places. A partial identification steps into the game, perhaps also with the people in the picture but certainly with the situation where they are. All and all, the text radiates a will to identify with another person's situation.

But what in this interpretation is now essential with regard to gender?

Though the writer gives meaning to gender in a binary way, s/he still opens an interpretation of the picture which calls into question the binarity that belongs to the heterosexual man/woman relationship. While the cultural meaning of the traditional family, as far as it constructs a shield against the outside world, is positioned to provide shelter to the lesbian relationship, it still disintegrates the traditional family model.

However, the meanings of the gender difference won't be left at this.

\section{Ethnicity}

When the gender of the person in the picture and, on the other hand, the central themes stressed in the interpretation of the picture are tabulated from the essays, the following pictures are created:

The Basic Frame of Interpretation

Person defined as a man $(\mathrm{N}=16)$

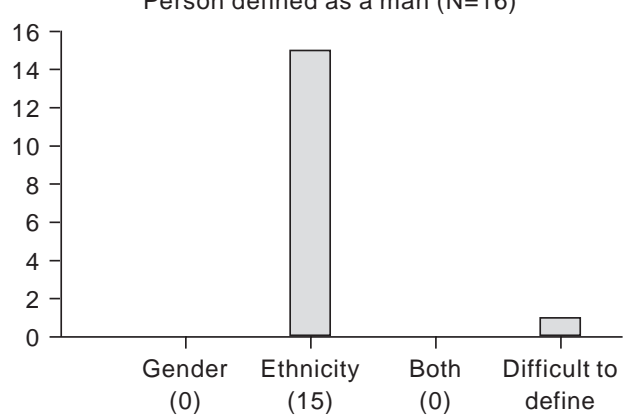

(1)
The Basic Frame of Interpretation

Person defined as a woman $(\mathrm{N}=20)$

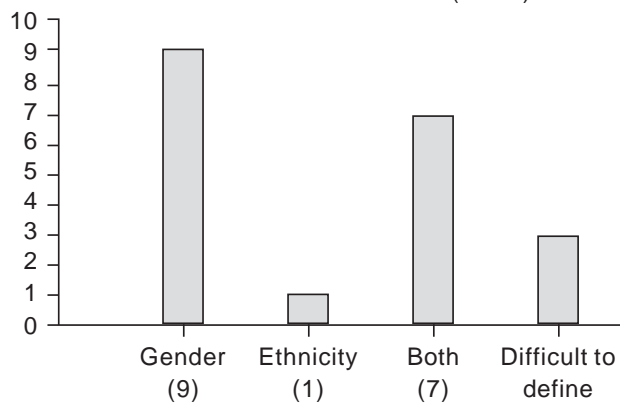

(3)

Of the writers who saw the person in the picture as a woman, 9 concentrated on contemplating only the gender difference, gender and ethnicity together was analysed by 7 writers, and only one discussed issues solely connected with ethnicity. Of those who defined the person as a man, 15 considered questions linked with ethnicity (race). Not one writer of those who interpreted the person as a man considered issues connected with gender difference. This is somewhat self-evident: those who saw a lesbian couple in the picture were naturally inclined to discuss gender differences. On the other hand, a heterosexual couple's cultural self-evidence excludes all consideration about gender. What is important here is that the gender construed to the person has an impact on how ethnic differences are taken under consideration. Only a few people who determined the picture's person as a woman bring up ethnicity and themes coonnected to race at all. However, the dynamics of interpretation also works the other way around: ethnic difference has an impact on how the theme of gender rises in the interpretations. It is apparent that the colour of a black person's complexion and his/her ethnic features make it more difficult to recognise gender. Moreover, the commonplace banality that also tells a lot about the eyes" capacity to make the distinction "all blacks look the same" dispels signs required for recognising gender from the picture. This is further assisted by the fact that the person's body is completely out of sight. This makes the writers inclined to act according to the norm Holly Devor mentioned earlier: in ambiguous situations, a person is commonly intepreted as a man. Additionally, there is rather a strong indicator of masculinity working in the picture: namely, the person's position in the family portrait. 
In the interpretations of the picture, gender difference and ethnic difference therefore determine each other. In the minds of the viewers, the person's identity and, via that, the central meanings of the picture are constructed at the intersection of these two different, but interdependent cultural discourses.

In the interpretations of most of the youngsters, the ethnic origin of the people is compressed into the characterisations dark/black and light/white woman or man and yellow/Oriental/Chinese child. In this sense, the picture indeed provides little information to the viewer, which in fact reinforces the aforementioned critique of Back and Quaade: In the Benetton campaign, people's ethnic and cultural backgrounds are reduced to the colour of their skin. However, in the young people's interpretations there are no direct traditional and crass strategies of racial stereotyping (such as, "a dumb negro"), which can even today be easily found within popular culture. The matriculation examination essay, though, requires political correctness and thus weeds out interpretative excess. It can also be considered how well the pair of opposites light/dark actually meets the characterisation of a binary difference. Light and dark can change into each other - even within the same ethnic group - with no clear borderline, whereas black and white are not able to do so. It may be that in fact a young person sees people that are hard to define by their ethnic origin in the picture, but linguistic expression as such is not flexible enough to make more subtle differentiations.

Many young people read the picture as part of the Benetton campaign to advocate for "racial equality". A good example is the following which represents a typical interpretation: "In the advertisement, a light-skinned woman, a dark-skinned man and an Oriental child are wrapped up in a colourful blanket to represent a multicultural family. Toscani has succeeded in capturing the beauty of serenity and expressionlessness. The picture taunts the viewer's racist mind in its praise of skin colour and equality in which different cultures exist in harmony with each other. Unprejudiced love between the human races makes the viewers consider their own level of tolerance, as well as become more international in this world." (11N5)

Here, the person on the right is understood as a man. Hence, the question is of a family whose most essential quality is its multiculturalism. Multiculturalism and "praise of equality" grow into a matter that begins to "taunt the viewer's racist mind". Moreover, in this interpretation the writer distances him/herself from his or her own immediate experi- ences and ponders which way the reception of the picture works. However, s/he does not closely define the viewer; the viewer is a generalised 'other' with no further precise qualities but perhaps a bit of a racist frame of mind. Or, does the characterisation "racist" refer to a potential that can be found in the mind of every viewer? Similar to the previous interpretation (2M1), the blanket acts as a metaphor for social bond that joins people to each other. Whereas the blanket previously signified a bond that sheltered a lesbian relationship, it has now grown into a metaphor which, in turn, creates a bond between the members of the family who represent many cultures and live "in harmony with each other".

Yet, does the space that is formed inside the blanket attempt to even out difference and similarity, or is it a question of space where difference is respected?

It is not quite simple to answer that question. One must begin from certain fundamental observations. First of all, not one of the writers directly interprets the picture in such a way that would promote racism or reinforce fears of homosexuality. Many writers do bring out the notion that the picture may provoke many such people who can not accept sexual or racial difference. Most writers take a positive stand on the idea of a multicultural family. Many also interpret the picture as advocating tolerance and equality. This becomes apparent for instance in the following ways:

The juxtapositioning is clear, but it communicates how in the end we all are equal regardless of our skin colour. (1M8)

In one of the pictures Toscani has portrayed a light and dark-skinned woman who hold a yellow-skinned, Asian child in their arms. Perhaps like this, with the aid of the colours of the picture, he creates an image of his dream: 'There is no racism in the world, but all are acknowledged as equal and everyone gets on with one another'. (18M9)

A white woman, a black man and a yellow child naked, wrapped up inside the same blanket. The man and woman's arms hold the baby in between them. This is one of Toscani's four photographs. The photograph takes a stance on human equality. Regardless of race, sex or age every human being is equal. The picture also communicates people's capacity to live and get on with each other in spite of their external differences. (21M10) 
All and all, in twelve interpretations concerning this particular picture it is said outright that the picture promotes equality. Four interpretations do not discuss equality, but similarity in the following way:

(T)he man and the woman's eyes that stare directly at the viewers make them stop to think how similar we people are after all. There is also fear in the eyes of the picture's man and woman, perhaps due to the judging outside world. (55N24)

In reality, all races form one species: regardless of their race, human beings are a uniform species. It is true that John Doe may have difficulties considering himself as similar to Zulu the Zairean. By similarity, I do not mean as much external similarity, but internal. Every human being, regardless of race, has human feelings. We are able to cry and laugh, get angry and relent, and love and hate. It is expressly these qualities that make us a uniform species. (57N25)

In the two latter quotes, abstract human similarity is emphasised at the cost of the differences; in other words, the significance of differences is disparaged and simultaneously their room for maneuver is reduced. In the last quote, race is also biologised: "all races form one species: regardless of their race, human beings are a uniform species." It can also be considered what kind of a stereotype is concealed in the expression "Zulu the Zairean". In the interpretations that emphasise equality, differences - not similarity - are instead the point of departure. In the first case, humanity returns to nature, outside of culture; in the latter, humanity is positioned in a cultural network of relationships in which differences are significant. The tension described here is at times also constructed in the interpretations within the texts: there can be references found to both directions in the same essay.

With regard to the "grammar of race" that Back and Quaade brought up, the decisive factor is whether people's conceptions of human equality are constructed on a certain principle which, in the end, ties people together, makes them similar despite difference. Or do the conceptions rely on the notion that there is no fundamental similarity, but equality is born in encountering and respecting difference. Both of these emphasises can be found in the young people's interpretations.

\section{Researchers and the Force of Criticism}

Naturally, the interpretations of two cultural researchers and young matriculation examination candidates are constructed from quite different points of departure. The mode of producing text is determined by the writers' cultural position, the possibility to delve into the subject, the audience of the text, the demands put on the text; all and all, the cultural margins of producing text. Moreover, it would be naíve to presume that the youngsters' interpretations would reflect their conceptions of racism or gender per se. The essays are rather a form of self-representation, expressions of oneself for the anonymous eyes of the judge on the matriculation examination board. This adds the element of a game, a play, a disguise to the essay-writing. You can dress up in opinions. Essay-writing is strategic writing, in which it is worth carefully considering what to put down on the paper. Yet, not all candidates give the issue much rational thought but write what feels the best.

It is also worth keeping in mind that the interpretations regarding an individual picture are isolated from the rest of the essays. A candidate might have written something in other sections of the essay which is not now revealed, but nevertheless important in regard to the interpretation of Family of the Future. For instance, there might be a quite directly put statement of how Benetton makes harsh business with its campaigns. The entire phenomenon called Benetton forms a framework through which the meanings of individual pictures are more built deductively, from general to private, than inductively, from an individual picture to a general phenomenon. Back and Quaade (ibid., 68) claim that Benetton presents the races as essential, immutable categories. This conceals the notion from sight that race is more a cultural construction than a biological fact. According to the researchers, Benetton's "grammar of race" therefore returns ethnic differences back into external racial features, such as the colour of skin.

When the young people's interpretations of Family of the Future are analysed, partially the same conclusion can be drawn. The youngsters use the concept of race in a contently unproblematic way, and at times repeat the interpetations Benetton has given to its campaign with no criticism (see www.benetton.com). Not one writer consideres the possibility of how the advertisements exploit racial 
stereotypes. The interpretations of equality are often idealised: the problematics of multicultural interaction do not arise. In the young people's interpretations, the concept of race is often - but not always - constructed in an essentialist and biological way. In spite of this, many remember to mention the possible difficulties people "of different races" may find themselves as they encounter racism. Hence, the young people may oppose racism, even though they determine race essentially, as a part of human being and not as a culturally constructed matter. This kind of a situation is quite interesting for cultural studies: what is the political significance of such racism-criticism the goal of which is 'right' but the points of departure 'wrong'? Can criticism against racism that springs from the 'wrong' starting points nevertheless lead into the direction of increasing social equality?

The problem is not limited merely to ethnic differences. The question is much broader and interconnected with relationships between consciousness, action and social change, the more detailed analysis of which is not the primary task of this article.

If the young people are partially held prisoners by the meanings Benetton itself gives to its campaigns, the more clearly it happens to the researchers - even if in a totally different way. Back and Quaade indeed tie their picture interpretations quite often with Benetton's own discourse, such as advertising brochures and press releases (see e.g. ibid, 68). They read what Benetton says about its campaigns and then criticise the pictures down under water, as if their meanings were even more generally constructed according to the Benetton interpretations. For this part, their criticism is valid only in the limits where the pictures are really interpreted according to the public image Benetton provides of itself. (This, naturally, only on the presupposition that the researchers' criticism is valid in the first place.)

In the young people's interpretations there are much more subtle and nuanced meanings constructed that one would expect on the basis of Back and Quaade's article. For instance, the ambivalence of the writers between equality and similarity tells about how racialising is much more complex than the researchers ever imagined. Neither do the researchers pay any attention of the role of the blanket. Some youngsters interpret the blanket as providing an autonomous space and shelter for multiculturalism from the hegemony of the mainstream culture. Interpreting the set-up in the picture as a family produces in part the same meanings.
According to Back and Quaade (mt., 68-69) Family of the Future is a good example of what Roland Barthes calls a myth. With concern to this interpretation, it is fateful that in many youngsters' interpretations the problems a lesbian couple meet come forth genuinely. Some writings, for example, deal with the question of the right to adopt a child by a couple of the same sex, an issue which was keenly debated in the Finnish public arena the year that preceded the candidate's essay-writing. Not one of the essays takes a stand against homosexual unions. Back and Quaade's generalisation, according to which "race, femininity and childhood are articulated within a mutually reinforcing discourse, in which social constructions are naturalised by the association between women as nurturers and children as innocents" sorely misses its point. In most interpretations the people in the picture are resolute, adults capable of managing their own lives, far from embodying the role of a "caretaker". Or, as one young person writes about the issue: "In a slightly ironic way, Oliviero Toscani is communicating that for two women in love the only way to have a child is adopted, providing that it is desired that men keep totally out of the picture."

The researchers' interpretations are above all undermined by the fact that the young people define the person in the picture now as a man, now as a woman. Though Back and Quaade underline the versatility of the interpretations aroused by the Benetton pictures, this kind of an effect has hardly even crossed their minds. For Back and Quaade, the person on the right is plainly a woman. However, they are not able to see the picture's homosexual meanings that are connected to the gender difference, which surely enough are served on a plate also to critical professional researchers. Neither do they understand how ethnicity and gender determine each other in the picture. Certainly it can be claimed that Back and Quaade's concentration on the "grammar of race" is a conscious choice of limitation, that they were not even supposed to deal with gender. However, in this case gender and the differences connected with it are an essential part of the "grammar of race", since gender difference strongly determines how ethnicity becomes meaningful in the interpretations of the picture. Besides, I do not believe that it is a question of an intentional limitation. Rather the nearly paranoid rooting out the "grammar of race" provides Back and Quaade the opportunity to be politically correct, racism-critical researchers. Yet, the "grammar of race" grows into an ideological interpretative horizon which blinds the research- 
ers from seeing the everyday meanings of the picture. They can not see gender from race.

As a matter of fact, Back and Quaade offer no arguments whatsoever to support their myth-critical interpretation. It is precisely here where the dictatorship of a researcher's role steps into the picture. The researchers have read their Barthes and understand that a woman's role as a caretaker is a social myth. They interpret the picture through this analysis, which is provided for them as critical social

\section{Notes}

1. The picture Family of the Future can be found, like any other picture mentioned in the article, for instance on the Benetton web page www.benetton. com/wws/aboutyou/ucdo/index.html. The picture the matriculation examination candidates analysed differed from the Benetton advertisement in one respect: it did not have the Benetton logo in it at all.

2. The whole assignment was as follows: "On the cover of the notebook, there are samples of Oliviero Toscani's photographs which are used in advertising the Benetton products. The pictures have raised heated feelings around the world. In many countries, their publication is prohibited. Analyse the pictures and discuss why they charm, annoy, offend. Title your essay yourself."

3. The article is based on close reading of 59 Benetton essays. The writers were high school students between 17-19 years of age. The essays come from seven different schools, whose geographical and socio-economic backgrounds vary. I extracted the characterisations that concerned Family of the Future out of the essays. In the entire data, 37 essays make a reference to the picture in question. Men and women wrote about it equally often: 18 woman and 19 men discussed the picture at least with a few sentences. After the process I studied which themes or frames appeared to be central in the fragments concerning the picture.

4. As is well-known, in english language there are two concepts the (biological) sex or (social) gender. When I use the concept myself, I refer to the social gender in the sense that Holly Devor (1989, vii) ) gives it: "Persons social status as either a man (boy) or a woman (girl)".

5. The candidates were not given the name of the picture Family of the Future.

6. As an expression, the heterosexual matrix is not among the most apt, since it gives the impression of a strict and deterministic cultural structure which does not leave room for critical agency. Butler herself, however, does not believe in the watertight determinism of the heterosexual matrix (see Butler 1993, 1-19). scientists. However, they do not mention at all who, in fact, is the subject of the interpretation. The unspecific quality of the subject universalises the researchers' interpretation and cleanses the agenda from the question of in which historical space, to whom, and on what preconditions the picture constructs mythical conceptions. Myth-critical researchers' interpretation in itself is mythical as it forgets its own historical quality.

\section{References}

Aarva, Pauliina (1991) Terveysvalistuksen kuvia ja mielikuvia. (Pictures and Images of Health Education) Acta Universitatis Tamperensis. Ser A; vol. 328. Tampere: University of Tampere.

Back, Les and Quaade, Vibeke (1993) Dream Utopias, Nightmare Realities. Imagining Race and Culture within the World of Benetton Advertising. Third Text 22(1993), 65-80.

Butler, Judith (1990) Gender Trouble. Feminism and the Subversion of Identity. New York: Routledge.

Butler, Judith (1993) Bodies That Matter. On the Discursive Limits of "Sex". New York: Routledge.

Devor, Holly (1989) Gender Blending. Confronting the Limits of Duality. Bloomington (Ind.): Indiana University Press.

Falk, Pasi (1997) The Benetton-Toscani Effect: Testing the Limits of Conventional Advertising. In Mica Nava, Andrew Blake, Iain MacRury and Barry Richards (eds.) Buy This Book. Studies in Advertising and Consumption. London: Routledge, pp. 64-83.

Giroux, Henri A. (1994) Consuming Social Change: The United Colors of Benetton. In Henri A. Giroux: Disturbing Pleasures. New York: Routledge. pp. 5-24.

Hall, Stuart (ed.) (1997) Representation: Cultural Representations and Signifying Practices. London: Sage.

Shapiro, Michael (1996) Images of Planetary Danger Luciano Benetton's Ecumenical Fantasy. In Tuija Parvikko and Jukka Kanerva (eds.) Exploring the Chronospace of Images. Jyväskylä: University of Jyväskylä, pp. 9-33.

Tinic, Serra A. (1997) United Colors and United Meanings: Benetton and the Commodification of Social Issues. Journal of Communication 47(1997):3, pp. 3-25.

\section{Translation:}

Aijaleena Ahonen and Kris Clarke

Published earlier in Tiedotustutkimus 23(2000)2: pp. 20-35. 